\title{
Recepción de la filosofía del lenguaje de K.-O. Apel en castellano
}

\author{
CRISTINA CORREDOR \\ Universidad de Valladolid
}

K.-O. Apel: Semiótica filosofica. Ed, trad. y estudios introductorios de J. de Zan, R. Maliandi y D. Michelini, Buenos Aires, Almagesto (imp. 1994).

J. J. Acero: «La recepción de la filosofía analítica por Apel: el significado y su validez;, en D. Blanco Fernández, J. A. Pérez Tapias, L. Sáez Rueda (eds.), Discurso y rea* lidad. En debate con K.O. Apel, Madrid, Trotta, 1994, pp. 115-130.

I

H. Schnädelbach ha señalado que la explicación conceptual sistemática - la aclaración y explicación de la red conceptual por medio de la cual se describen e interpretan las experiencias - y el dominio de la fundamentación de normas - la investigación critica de las condiciones normativas que hacen posible esas expericncias y su expresión-son, hoy en día, las dos cuestiones más específicamente filosóficas. Remiten al ámbito de la realidad factica en el cual las experiencias tienen lugar y al ámbito discursivo de la argumentación reflexiva y crítica acerca de las elaboraciones lingüísticas que han permitido expresarlas. Desde un perspectiva filosófico-lingüística, en el primer ámbito se constituye el sentido que luego expresan el conjunto de significados lingüísticos de las lenguas naturales; el segundo permite justificar la validez del sentido así constituido, y esto quiere decir: mostrar que se trata de un sentido intersubjetivamente válido. Puede darse un paso más y definir la noción de significado como sentido intersubjetivamente válido. El lenguaje pasa a ser así la institución cons- titutiva de todo lo que pertenece al sentido intersubjetivamente válido. Con ello se asume una tesis fuerte, que despues habrá de respaldar una teoría del significado desarrollada en detalle: la que afirma el vínculo interno entre significado y validez.

Esta tesis es central para la filosofia del lenguaje de K.-O. Apel, que él ha llamado pragmática trascendental, y está en la base del giro lingüístico que desde finales de los sesenta ha caracterizado a su pensamiento. Es por ello un acierto haber elegido la contraposición entre realidad $y$ discurso -o entre facticidad e idealidad, o particularidad y universalidad - como tema general común para un conjunto de ensayos que se ocupan de distintos aspectos de la obra filosófica de Apel. De hecho, los dos libros a que se hace referencia son testimonio de un interés reciente por hacer accesible esta obra mediante traducciones y estudios, interés que ha estado presente desde la publicación de Transformación de la filosofía (Madrid, 1987). Esta atención está teniendo lugar simultáneamente en el ámbito angloamericano y, así, la New School for Social Research ha promovido la traducción al inglés de una selección de 
ensayos de Apel (New Jersey, Humanities Press) sobre filosofia del lenguaje (vol. 1) y ética y teoría de la racionalidad (vol. 2). Pero no es menos cierto que Apel es conocido sobre todo por ser el creador, junto con J. Habermas, de la ética del discurso, así como - frente a éste-por'su defensa de una filosofía pragmática trascendental que permita una fundamentación última. Ello ha hecho que se haya considerado a su teoría semiótica y a su filosofía del lenguaje en general sólo con un carácter subsidiario, en tanto que motivadas por las necesidades de fundamentación de una filosofía moral que asume el giro linguiistico en filosofia y hace del universalismo y del carácter dialógico, comunicativo de la razón sus señas de identidad.

Creo, sin embargo, que esta filosofia del lenguaje tiene una entidad propia que hasta ahora, por la falta de traducciones al castellano, ha permanecido casi ignorada entre nosotros. Si bien es cierto que Apel ha asumido explícitamente las tesis centrales de la teoría pragmática universal del significado de J. Habermas, no lo es menos que sus propios análisis de las distintas concepciones del lenguaje, tanto históricas como contemporáneas, y su semiótica filosófica -que parte de la trasformación semiótica de la filosofía trascendental de Kant por Ch. S. Peirce- manifiestan una originalidad y una potencia de pensamiento que han sido fértiles tanto al influir en sentido inverso sobre Habermas como al sugerir, con sus argumentos y observaciones, posibles líneas de crítica. Más aún, es imprescindible leer la ética discursiva de Apel desde la teoría del significado y la semiótica filosófica que constituyen su fundamentación. En este sentido resultan particularmente aclaradores los tres estudios introductorios de $J$. de Zan, R. Maliandi y D. Michelini. El primero se centra en la propuesta filosófico-lingüística de una pragmática trascendental, esforzándose por precisar los conceptos filosóficos centrales puestos en juego; el segundo explica el modo en que esa filosofia del lenguaje permite fundamentar las tesis básicas de la ética discursiva; finalmente, el último se ocupa de la teoría de la racionalidad que resulta de estos desarrollos previos.

\section{II}

En lo que sigue voy a centrar la atención en el único cnsayo de Discurso y realidad que se ocupa, explícitamente, de una crítica a la filosofía del lenguaje de Apel y, en particular, a su interpretación del Wittgenstein de las Investigaciones filosoficas $(I F)$. Sin que esto suponga una descalificación global de su estudio, creo sin embargo que J. J. Acero no llega a identificar un problema central al que intenta responder el planteamiento de Apel. Su análisis toma en consideración en gran medida un ensayo aún no publicado de éste, por lo que algunas de las observaciones que siguen podrian no ser enteramente justas. Por otra parte, puesto que la crítica de Acero se restringe al analisis de lo que se ha llamado el uso epistémico (o cognoscitivo) del lenguaje y de la noción de validez epistémica (verdad) correspondiente, también se hará así aquí.

J. J. Acero atribuye a Apel lo que se ha denominado una «interpretación comunitaria» de Wittgenstein, basada en la lectura de $P$. Winch. Según ésta, la noción de regla y el seguimiento de reglas sólo puede explicarse por referencia a alguna comunidad linguística; únicamente habria conducta lingüística ajustada a reglas cuando aquélla sigue pautas vigentes o sancionadas como válidas por una instancia pública o comunitaria de control. El paso a una pragmática trascendental lo da Apel cuando defiende una dimensión nomativa que guía las elaboraciones fácticas y que remitiría a una comunidad ideal de comunicación que, además de un ideal regulativo, es vista también por Apel «como principio 
constitutivo del contenido de conceptos, del significado de las palabras y, en general, de la validez de las normas sociales» (Acero, ibid., p. 121). Esto supone la defensa de una tesis más fuerte acerca de la relación entre pensamiento (o mente) y lenguaje, tesis a la que Acero atriburye una unidireccionalidad radical que no existe en Apely que probablemente motiva su fuerte rechazo crítico.

No cabe duda de que Apel ha defendido que la intencionalidad de la mente no es originaria; lo ha hecho en el curso de su crítica a la fenomenología trascendental de Husserl y a las concepciones intencionalistas del lenguaje (cf. e. g. Apel, Semiótica filosófica, cap. 3). Pero afirmar que xla relación entre mente y lenguaje resulta ser la inversa de la propugnada por el solipsismo metodológico" (Acero, ibid., p. 121) supone atribuirle lo que Apel mismo en otros lugares ha denunciado como una falacia idealista. Aquí es preciso tener en cuenta la distinción introducida al comienzo entre lo que constituye el sentido y lo que justifica la validez intersubjetiva del sentido constituido. En su lectura crítica del último Searle, Apel reprocha a éste el tomar, como condición para su teoria del significado, la de una dependencia unilateral del significado lingüístico con respecto a la intencionalidad de la conciencia, de la que se alega que es más fundamental... en contraste con ello me gustaría proponer, para los casos normales de enunciados asertivos y convicciones básicas, la tesis de una dependencia recíproca del apriori de la conciencia y el apriori lingiaistico» (Apel, «Is intentionality more basic than linguistic meaning?», en $E$. Lepore y R. v. Gulick (eds.), John Searle and his critics, Oxford, 1991, pp. 31-55, aquí p. 41).

Precisamente, lo que Apel critica a una parte de la filosofia analítica del lenguaje es su exageración semanticista, que llega a rechazar la posibilidad misma de examinar las teorías por medio de la expe- riencia libre de teoría. Existiria una diferencia incuestionable entre los enunciados libres de evidencia y los juicios de percepción «que introducen de manera ejemplar, por así decirlo, nuevos predicados, atendiendo a cualidades $y$ relaciones que se hacen presentes con respecto a determinados objetos deícticamente identificables» (Semántica filosófica, p. 322). Pero tampoco es posible retroceder a una teoría de la verdad como evidencia en el sentido del solipsismo metodológico de Husserl o de las modernas teorías de la intencionalidad. La mediación necesaria entre la evidencia fenomenológica y la semántica filosófica se hace posible en la semiótica de Peirce y su diferenciación de tres categorías semióticas fundamentales («primeridad», "segundidad", «terceridad») unidas a tres tipos de signos correspondientes (iconos, índices, símbolos). La evidencia libre de teoria de la representación de un estado de cosas en los juicios de percepción se apoya solamente en las funciones no simbólicas (i. e. no referidas a conceptos) que los signos lingüísticos pueden cobrar en el contexto de las situaciones de percepción. Estas funciones no simbólicas son: 1. Funciones deícticas (indexicales) de los términos identificatorios (pronombres demostrativos, nombres propios, adverbios de lugar y de tiempo); la función indexical del signo asegura, en el acto de la identificación del objeto, el contacto real de la percepción con la existencia y la afección causal de lo real independiente de la conciencia. 2. Funciones cuasi-icónicas de las predicaciones; dirigen la atención a las caracteristicas cualitativas fenoménicas de las propiedades y relaciones entre objetos.

Pero «este aseguramiento semiótico (esto es, posibilitado por las funciones no simbólicas del lenguaje), de la evidencia libre de interpretación de la representación lingüistica del mundo, no fundamenta todavía sin embargo, según Peirce, ningún conocimiento intersubjetivamente valido... Para esto se requiere todavía el juicio de la per- 
cepción, el cual, de acuerdo con las posibilidades, hace intervenir ahora el rendimiento interpretativo de los simbolos conceptuales del lenguaje dependiente de la tradición» (ibid., p. 324). Incluso en el pensar solitario con prestación de validez o en el conocer «algo como algo» está implícito, por tanto, el presupuesto necesario de la intersubjetividad comunicativa. Esto significa que una mente individual no podría pensar con pretensión de validez, si al hacerlo hubiera "puesto entre paréntesis" el lenguaje y la comunidad de comunicación que ello presupone (ibid, p. 173). La tesis que sí defiende Apel, sin ninguna ambigüedad, es la de que el pensamiento puede verse como comunicación internalizada.

Esta afirmación se justifica porque, de acuerdo con la teoría semiótica de Peirce, el momento fenomenológico de la experiencia, en cuanto experiencia precomunicativa inmediata, sólo puede aprehenderse en su objetivación linguística. Esta objetivación tiene lugar, en primer término, en el horizonte de sentido ya dado, en el seno de los significados constituidos históricamente y social e institucionalmente aceptados, que cabe reconstruir como convencionales (sentido preconstituido de los símbolos conceptuales). La problematización de estos significados fácticos puede provenir de la experiencia prelingüística; pero lo que justifica la validez del nuevo sentido constituido (a través de la introducción, p. ej., de nuevos símbolos conceptuales) no es una correspondencia ingenuamente "recuperada", sino su resolución mediante un proceso de entendimiento entre sujetos alcanzado argumentativamente. La experiencia entra en juego como referente necesario; pero la revisión crítica de las convenciones de significado a que da lugar no arroja nunca el resultado de un acceso a lo «originario» en la experiencia, o una superación de las mediaciones lingüísticas - por el carácter convencional o institucional del lenguaje. Esto, sin embargo, no disuelve la idea de validez: por el contrario, pone de manifiesto la dimensión normativa presente en la justificación de la validez de los significados constituidos $\mathrm{y}$, por consiguiente, en la necesidad de recuperar reflexivamente las condiciones que hacen posible que la propia experiencia se objetive en el lenguaje - lo que supone una remisión incvitable a un entendimiento con los otros. Para Apel, lo trascendental está en la intersubjetividad entendida como condición de posibilidad del entendimiento entre quienes establecen una comunicación lingüística.

La noción de racionalidad que entra aquí en juego no es la de una facultad que "constituye» la experiencia o que tiene precminencia sobre esta, sino la de una competencia que permite recuperar y reconstruir lo pre-racional y justificar la validez del sentido que surge espontáneamente; y lo hace en el contexto de la comprobación fáctica de esa validez, en el transcurso de procesos de aprendizaje y procesos de revisión de lo previamente constituido. Pero lo último tiene lugar necesariamente en el contexto del habla argumentativa, o discurso; éste se caracteriza porque en él los participantes elevan con sus actos de habla (unidades mínimas de significado) pretensiones de validez universal (verdad, rectitud, veracidad), y asumen tácitamente presupuestos de carácter normativo.

El ensayo de Apel en que se basa Acero se ocupa en particular de lo que se llama el argumento de los imconprendidos, que permite a Apel explicar el proceso que lleva a que nuevos significados (p. ej., mediante la introducción de nuevos términos, o el recurso a las funciones no simbólicas del lenguaje) alcancen validez intersubjetiva. Acero reconstruye la argumentación de Apel a partir de cinco premisas y una conclusion, cuya validez cuestiona: pues «ni la premisa $\left[\mathrm{P}_{3}\right]$ ni la premisa $\left[\mathrm{P}_{5}\right]$ me parecen verdaderas". $\left[\mathrm{P}_{3}\right]$ se enuncia: *El concepto de comunidad es un 
ingrediente constitutivo del de regla»; $\left[\mathrm{P}_{4}\right]$ es: aEl estudio empírico de los usos lingüísticos no puede proporcionar nunca evidencia concluyente para decidir la cuestión de derecho" (Acero, ibid., pp. 124, 123). La primera de las dos premisas, $\left[\mathrm{P}_{3}\right]$, constituye lo que Acero denomina una interpretación comunitaria del seguimiento de reglas. Frente a esta interpretación, Acero defiende otra lectura: la que permite atribuir a un sujeto que actúa monológicamente el seguimiento de reglas «privadas», capaces de cristalizar en una costumbre. Acero intenta mostrar, frente a ello, cómo en Wittgenstein quedaria abierta la posibilidad de que una regla pueda ser seguida por un solo individuo; lo que en las $I F$ se establece sería el requisito de una pluralidad de usos de la regla, pero no de una pluralidad de usuarios (ibid., p. 125). Con ello, la noción de regla en Wittgenstein sería compatible con una concepción del significado que considere la intencionalidad de la mente originaria con respecto al lenguaje.

Sin duda Acero tiene razón en su precisión (ibid., n. 13) acerca de lo que la proposición $I F, \S 199$, literalmente dice; «No puede haber una única vez en que un hombre siga una regla.» La regla implica una pluralidad de aplicaciones: una regularidad cristalizada en costumbre («usos, instituciones»). Pero concluir que ello es compatible con que sí pueda haber un único hombre que establezca reglas para sí mismo está tan lejos de constituir una inferencia lógica como la lectura de Apel, quien «atribuye a Wittgenstein la afirmación de que ningün hombre puede seguir una regla para él solos (ibid.). De hecho, Acero omite en su corrección de la cita lo que precede y sigue inmediatamente a esa afirmación de Wittgenstein, y el contexto podría resultar en este caso particularmente importante para la interpretación. En sentido estricto, la lectura «solipsista» que Acero propone es posible. Pero él prescinde en su discusión de que
IF, $\$ 199$ consiste en una respuesta negativa a la pregunta explícita por la posibilidad de que pueda hablarse de un único usuario: «iEs lo que llamamos "seguir una regla" algo que pudiera hacer sólo un hombre sólo una vez en la vida?» $\mathrm{Y}$, aunque la respuesta de Wittgenstein prescinde de volver a enfatizar la negación ( $\mathrm{No}$... un [solo] hombre...») en lo relativo al hablante -al «seguidor de reglas»--, el tipo de reglas a que se hace referencia como ejemplos implican, necesariamente, la presencia de un interlocutor: «No puede haber sólo una única vez en que un hombre siga una regla. No puede haber sólo una única vez en que se haga un informe, se dế una orden, o se la entienda, etc.» Neccsariamente también, por tanto, la regla tiene que ser tal - tiene que ser reconocible, y por tanto compartida- para los participantes en la interacción. Si Wittgenstein, en este contexto de ejemplos, hubiese vuelto a enfatizar: «No... un [solo] hombre... haga un informe, ... dé una orden, o... la entienda", estaria en el mejor de los casos siendo redundante. Pues esta última parte de la proposición entraña - desde el punto de vista formal-pragmático- una respuesta negativa a la totalidad de lo cuestionado.

Lo que parece ser el principal punto de desacuerdo con la perspectiva kantiana de ApeI se encontraría, sin embargo, en la premisa $\left[\mathrm{P}_{s}\right]$, a la que Acero atribuye acertadamente un carácter fundamental. En efecto, como ya se ha dicho, para Apel «el estudio empírico de los usos lingüisticos no puede proporcionar nunca evidencia concluyente para decidir la cuestión de derechon (Acero, ibid.). Este es precisamente el punto en el que Apel ha discrepado de J. Habermas; el último ha defendido que sí son las ciencias empíricas las que, de modo progresivo, pueden ir iluminando y proporcionando el suficiente apoyo a la reconstrucción de carácter fillosóficos que las precede. Ello manteniendo al mismo tiempo una perspectiva kantiana en relación con la presencia de presupues- 
tos normativos en la comunicación - aun sin el salto «trascendental» y haciendo igualmente la interpretación comunitaria de Wittgenstein que Acero critica. Esto fuerza a precisar mejor, en el contexto de la teoría del significado de la pragmática universal propuesta conjuntamente por Apel y Habermas, qué noción de regla entra en juego, qué se entiende por noma o normativo, y en qué sentido estas nociones se vinculan con la realidad fáctica de los usos del lenguaje, con lo empíricamente describible.

La noción de regla entendida normativamente, en su sentido kantiano, es distinta de la que puede explicarse en términos de regularidades o convenciones obscrvables, en un sentido wittgensteiniano. Esta distinción, que Acero pasa por alto en su crítica, es fundamental en el presente contexto (cf. e. g. J. Habermas, Moralbewußssein und kommunikatives Handeln, Francfort, 1983, pp. 97-104). Las reglas del habla argumentativa, aquellas a las que se atribuye un carácter normativo, no son constitutivas en el mismo sentido en que lo son las reglas del ajedrez. Pues, mientras éstas determinan fácticamente la práctica del juego que constituyen, las primeras no son constitutivas en el sentido de que proporcionen una determinación de hecho para un tipo de actividad, ni son susceptibles de ser descritas como convenciones. Las reglas del habla argumentativa son una forma de representación de los presupuestos pragmáticos que caracterizan esta práctica comunicativa, tácilamente aceptados y asumidos por los participantes en la comunicación. Si se compara la práctica del ajedrez con la de la argumentación, los equivalentes de las reglas del ajedrez serían aquellas reglas de la argumentación que, de hecho, se siguen cuando se elaboran e intercambian argumentos. Las reglas normativas de la argumentación señalan a las condiciones que los participantes han de suponer suficientemente satisfechas, si es que pretenden validez para sus argumentos. En este sentido, se trata de reglas que rigen contrafácticamente. Los presupuestos pragmáticos universales (máximamente generales) y necesarios (inevitables) que representan estas reglas incluyen: 1. El reconocimiento del derecho de todos aquellos capaces de habla y acción a participar en la argumentación. 2. En el transcurso de estos procesos argumentativos todos se encuentran en una posición de reciprocidad igualitaria, en el sentido de que tienen igual derecho a intervenir, a introducir nuevos temas, a solicitar que se reflexione sobre o que se revisen los presupuestos de la conversación, etc. A las prácticas argumentativas guiadas por el respeto a estos presupuestos, Apel les da el nombre de comunidad ideal de comunicación.

Evidentemente, si no se trata aquí únicamente de la caracterización definicional de una forma ideal de comunicación, es preciso mostrar que ken el caso de las reglas del discurso no se trata simplemente de convenciones, sino de presupuestos irrenunciables» (ibid., p. 100). Lo que está en el trasfondo de esta distinción tiene que ver con una dificultad central para la propuesta que se está elaborando: el riesgo de una caída en una teoría pragmatista puramente descriptiva y que no pueda evitar el relativismo - algo que tanto Habermas como Apel reprochan a Wittgenstein, y que invalidaría la pretensión de univer. salidad de la teoría que estos autores proponen. Pues estos presupuestos contrafácticos sólo pueden identificarse cuando se adopta la perspectiva de un participante en la interacción: "Con ello hemos de apelar a la precomprensión intuitiva con la que todo sujeto capaz de lenguaje y acción entra en la argumentación» (ibid.). Para salvar el universalismo, Apel ha recurtido al argumento de la inevitable caída en una contradicción realizativa (performativer Widerspruch) siempre que se intenta negar la validez de estos presupuestos. Su discrepancia con Habermas reside en que, 
para Apel, el único ámbito comunicativo en el que es posible identificar estos presupuestos normativos en actitud reflexiva, y mediante la aplicación metodológica de principio de no-autocontradicción realizativa, es el del discurso argumentativo en el que se trata de la justificación de pretensiones de validez problematizadas y de la fundamentación de normas. Mientras, Habermas, sobre la base de la tesis que afirma la preeminencia nomativa del uso comunicativo del lenguaje (orientado al entendimiento) sobre otros usos estratégicos, considera posible acceder a los presupucstos universales $\mathrm{e}$ incvitables $\mathrm{dc}$ la comunicación a partir de la investigación empirica (cf. Semiótica filosófica, pp. 119-149.)

En su critica a Apel, Acero atribuye a una cstrategia kantiana el verse obligado, a partir de las premisas $\left[\mathrm{P}_{3}\right]$ (que «sienta ciertos hechos acerca de la necesidad o normatividad de nuestra experiencia $\operatorname{cog}$ nitiva»), $\left[\mathrm{P}_{4}\right]$ (los «incomprendidos» que introducen innovaciones siguen correctamente reglas) y $\left[\mathrm{P}_{5}\right]$ (premisa «deflaccionista», «relativa a las limitaciones de nuestros sistemas sensoriales»), a postular una instancia trascendental, la comunidad ideal de argumentación. Acero cree que, al igual que Kant, «tampoco toma Apel una sola medida que respalde $\left[\mathrm{P}_{5}\right]$ " (Acero, ibid., p. 127). Frente a esto, él defiende que «el paso de la norma a la regularidad es mucho más directo y legítimo de lo que $\left[\mathrm{P}_{5}\right]$ aseguran (ibid., p. 126). Es evidente que esta afirmación no toma en cuenta la distinción conceptual precedente; pero tampoco podría dar razón de ella desde la tesis fuerte que parece defender: para que algo «posea» significado, es preciso que esté «tocado con el don de la intencionalidad»; $\mathrm{y}$ «alli donde hay intencionalidad, hay una regla" (ibid). Paradojicamente, Kant no habría estado en desacuerdo con estas últimas afirmaciones; forman parte, inequivocamente, de lo que se ha llamado el paradigma de la filosofía de la conciencia - la que concede preeminencia a la intencionalidad de la mente y a las categorías y principios presentes en la conciencia, de los que hace depender toda otra elaboración o práctica. Pero, lo que es más importante, Acero parece pasar por alto un problema central, precisamente el que crea dificultades a la posición intencionalista que él parece defender y que constituye la preocupación fundamental de la filosofía de la intersubjetividad que él discute: el de cubrir el salto conceptual que hay desde una conciencia solipsista a 10 compartido de forma pública y con validez intersubjetiva.

El universalismo que Kant había hecho descansar en los conceptos y principios $a$ priori de la razón resultó inmediatamente puesto en cuestión por la crítica linguiística que le dirigieron J. G. Hamann, J. G. Herder y W. v. Humboldt. Estos autores pusieron de manifiesto que no podía decirse, de las categorias y principios kantianos, que procedicran de un ámbito prelingüistico (mente o conciencia); puesto que sólo accedemos a ellos en la mediación del lenguaje, lo que caracteriza a esa intencjonalidad supuestamente originaria de la conciencia es su lingüisticidad y, por ello, el que sus contenidos (los conceptos y sus relaciones) son siempre relativos a un contexto social e histórico. Hegel extrema esta idea al "tender el puente» dialéctico entre sujeto y objeto y considerar la realidad objetiva como la fusión de objeto y concepto -este último, necesariamente lingüístico-; la realidad objetiva, ya sea material o socio-histórica, tiene una legalidad propia de la que la subjetividad es un elemento integrante activo.

Como Ch. Taylor ha señalado («Theories of meaning", en Philosophical papers, Cambridge, 1985 , pp. 248-292), la crítica lingüistica a Kant lleva a poner de manifiesto cómo al lenguaje le corresponde, además de las funciones representativa y expresiva, una función constituyente -que puede explicarse, de nuevo paradójica- 
mente, tomando las palabras del propio Acero: «el lenguaje no es sólo un medio de expresión, sino también un medio de constitución del pensamiento" (Acero, ibid., p. 127). Pero lo que entra en juego aquí no es la oposición solipsismo/intersubjetivismo, sino la dificultad aludida antes y que Acero no llega a tratar, quizá porque asume a su vez otra premisa. El «lenguaje» no aparece nunca en singular: to que hay son lenguas, en plural, y de cada una de ellas puede decirse que incorpora una concepción del mundo (Humboldt), históricamente constituida e irreductiblemente diversa. Desde la perspectiva de esta crítica no parece correcto, como hace Acero, poner en correspondencia $\left[\mathrm{P}_{5}\right]$ con la consideración kantiana de que lo dado a la intuición es una pluralidad de sensaciones dispersas; más bien, esta diversidad epistémica estaría ahora en correspondencia con la diversidad de las lenguas naturales. Aceptar que el lenguaje tiene una función constituyente respecto a esta imagen del mundo equivale a hacer descansar en el lenguaje (en cada lengua) los rendimientos que Kant atribuía a una conciencia trascendental. $Y$ entonces se hace difícil dar cuenta de algo que Acero no llega a discutir: que «la incorrección de [una] representación» pueda establecerse en absoluto, y ello whaciendo constar pura y simplemente el hecho de que...» (ibid., p. 126).

Si uno se toma en serio la función constituyente del lenguaje, entonces -como lo muestra Taylor desde su posición hegeliana- tanto lo que se toma como hecho, como la configuración de objetos que lo integran, como el procedimiento que permite shacerlo constar» son absolutamente relativos al contexto histórico, social y cultural. $Y$ este relativismo alcanza inevitablemente al planteamiento intencionalista: pues tiene que «saltar» desde los contenidos intencionales prelingüísticos a las convenciones (lenguaje como institución) que permiten expresarlos, y para ello ha de postular que las condiciones de satisfacción de los actos de habla coinciden con las del acto intencional, el cual es originario con respecto a su expresión. El cómo es posible que estas condiciones, originariamente extralingüísticas, sean exactamente las que se encuentran lingüísticamente reflejadas mediante las expresiones convencionales de las distintas lenguas naturales no queda satisfactoriamente contestado sin dar respuesta a la crítica lingüística a Kant.

El propio J. Searle lo ha formulado asî: «a clave para el problema del significado reside en ver que, en la realización del acto de habla, la mente impone intencionalmente, sobre la expresión física [e. d. lingüística, C. C.] del estado mental expresado, las mismas condiciones de satisfacción que el estado mental posee en sí mismo» (Intentionality, Cambridge, 1983, p. 164). Pero, o bien se asume una posición naturalista y se supone que las representaciones intencionales se corresponden con la estructura real de los hechos, es decir, que las «afecciones en el alma» son signos de las cosas mismas $-\mathrm{y}$ esto obligaría a remitir toda la construcción al ámbito normativo desde el que se justifica la validez de esta posición epistemológica-, o es algo que meramente se constata: pero sólo lo pueden constatar aquellos que pertenecen a un mismo contexto cultural y a una misma comunidad linguística, con lo que han tenido acceso a todos los preparativos lingüísticos que permiten nombrar objetos y representar hechos (Wittgenstein, $I F)$. En ese caso, el trasfondo del que habla Searle, la comunidad lingüística a la que se pertenece, es elemento necesario para tener acceso a la intencionalidad de la propia conciencia. Pero además, y excepto si se recurre al postulado del presupuesto naturalista anterior, no es posible salvar el inevitable relativismo ligado a la aceptación del valor constituyente del lenguaje para la imagen del mundo. Esto afecta a toda la discusión de Acero relativa 
a si es posible (o no) atribuir el seguimiento de reglas a un sujeto solitario. La cuestión no es que él mísmo pueda darse reglas o no, sino que, cuando lo hace -como el ejemplo de Rubinson, que Acero menciona, pone particularmente de manifiesto-, necesariamente parte ya desu propia experiencia linguística y de su conocimiento de las reglas semánticas y pragmáticas que permiten emplear signos; en este sentido es ya, por así decir, un «competente seguidos de reglas».

La noción que la teoría intersubjetiva del significado introduce en correspondencia con (y como contrapuesta a) la de condiciones de satisfacción (o de éxito) de los actos de habla es la de condiciones de aceptabilidad. Ambas remiten a la oposición de tacionalidad comunicativa/racionalidad estratégico-instrumental, y constituyen asî la principal modificación que la teoría pragmática universal del significado lleva a cabo a partir de la teoría de actos de habla. Pues lo que en primer término aparece como condiciones de éxito (de un acto de habla) es idéntico a lo que Austin había introducido como condiciones de logro (o éxito) en la comunicación y que después Searle desarrolló bajo la categoría de condiciones de sutisfacción - como re-elaboración pragmática de la categoria semántica de condiciones de verdad. Searle reconstruía estas condiciones como condiciones necesarias y suficientes para la realización con éxito de la comunicación -y ello podría ser visto, a su vez, como un conjunto de reglas para la comunicación con éxito de la fuerza ilocutiva que acompaña al contenido proposicional. En cualquier caso, el vinculo entre las condiciones (pragmáticas) de satisfacción o éxito y el logro alcanzado en la comunicación -incluido el entendimiento de la fuerza ilocutiva - sólo la establecía Searle con una pretensión de adecuación descriptiva: se explicaba en términos de regularidades tácitamente conocidas por los hablantes y empleadas por ellos, que se veían remitidas -en última instancia- a convenciones de carácter pragmático.

De ahi que la aparentemente fuerte confrontación entre esta concepción «convencionalista» del lenguaje (teoria institucionalista del significado) y una concepción intencionalista no obligue a Searle, en su segundo planteamiento intencionalista, a prescindir de la noción de condiciones de satisfacción/de éxito; ello, en la medida en que su nueva teoría sigue manteniendo una concepción del lenguaje entendido como un conjunto de convenciones o regularidades fácticas que permiten expresar contenidos intrapsiquicos, y se limita a discutir la prioridad de uno u otro elemento. Mientras las reglas constitutivas del lenguaje no son vistas como constitutivas de la interacción humana y del propio mundo de la vida, es decir, mientras no cobran un carácter normativo, y sólo pretenden adecuación descriptiva para regularidades fácticas, la teoría del significado resultante tampoco puede pasar de lo einstitucional» (convencional) a lo intersubjetivamente vălido.

A la contraposición entre condiciones de exito (contingentes, empiricamente identificables como regularidades) y condiciones de aceptación - de aceptabilidad- le subyace la tesis fundamental de que sentendemos un acto de habla cuando sabemos qué lo hace aceptable», que remite a su vez al ámbito normativo (contrafáctico) de justificación de la validez. $\mathbf{Y}$ esta tesis es a su vez dependiente del hecho de que la existencia de reglas intersubjetivamente compartidas hace a los actos de habla susceptibles de crítica, sobre la base de sus pretensiones de validez. En el marco de su defensa del habla argumentativa como el ámbito en el que es posible la auto-reflexión capaz de identificar los presupuestos normativos de la comunicación -presentes en este uso normativamente "prioritario" del lenguaje, y que constituiría una especie de límite trascendental respecto a otros usos, como el abiertamente 
estratégico-, Apel vincula la noción de condiciones de aceptabilidad a la de significado ilocutivo: su compromiso es con «una explicación posible del significado ilocutivo a la luz de las condiciones de validez en cuanto condiciones de aceptabilidad discursiva» (Semiótica filosófica, p. 133).

Viéndolo con un poco de maldad, podria decirse que el planteamicnto intencionalista vuelve a situarse en el punto de la polémica griega acerca de si los nombres son por naturaleza o por convención. Ante la constatación del carácter contingente (arbitrario) y fáctico (histórica y socialmente constituido) de los signos lingüisticos y la aceptación subsiguiente del carácter convencional del lenguaje, se hace preciso recuperar la posibilidad y validez del conocimiento suponiendo que nos hacemos representaciones correctas o susceptibles de revisión y corrección, que sólo después se expresan linguísticamente, de'tal forma que esta expresión refleja fielmente la estructura de nuestras representaciones cognoscitivas. Que podemos contar con esta garantía es lo que intenta hacer plausible el planteamiento intencionalista: puede aceptarse que los nombres son por convención, pero las representaciones intencionales son por naturaleza - no están «contaminadas» lingüísticamente. Con ello se pasa por alto el problema que se ha venido señalando; pero además se asume acríticamente, renunciándose a dar razón de ello, la posible y necesaria validez (corrección) en las representaciones, algo que despućs de Humboldt y Hegel necesita de mayor justificación o que, al menos, no puede verse como una cuestión de hecho. El problema con el planteamiento intencionalista y su recurso al trasfondo es que no puede dar cuenta de la cuestión de derecho relativa a cómo es posible justificar la validez de nuestras representaciones linguísticas, de un modo que trascienda la dependencia de ese contexto lingüístico y cultural.
La crítica lingüistica a la teoría del conocimiento de la filosofía de la conciencia -éste es el apriori que Apel asume, al atribuir al lenguaje un carácter al tiempo fáctico y trascendental - hace que ya no sea posible suponer que conocimiento designa algún tipo de proceso empírico que tiene lugar sin más mediaciones en la mente y con el concurso instrumental del lenguaje; no es posible hablar de conocimientos (representaciones correctas de la realidad) tan sólo desde el punto de vista de su génesis, y como una mera cuestión de hecho. Una representación no es un conocimiento sólo porque tenga lugar psiquicamente y de hecho con características determinadas, sino porque tiene una validez. Constatar esto aún no presupone nada acerca de en qué consiste esa validez: reconstruirla es el problema kantiano. Pero parece irrenunciable que la expresión «conocimiento» 0 "representación correcta» no designa un hecho, sino una legitimidad. El problema del conocimiento y de su validez en la inevitabilidad de su mediación lingüistica no es una cuestión de hecho, sino una quaestio iuris. Desde una perspectiva kantiana, lo verdaderamente central no es si lo dado a la intuición es (o no) «un flujo de sensaciones particulares, dispersas y desordenadas» - algo que, por otra parte, Kant acepta de Hume y es compatible con el conceptualismo lingüístico del empirismo tradicional; lo central es que la validez o legitimidad en cl conocimiento se alcanzan no en la génesis fáctica, sino en su demostración o su fundamentación.

$\mathrm{Y}$ aquí, en relación con esta cuestión de derecho, es donde entra en juego la transformación semiótica y pragmática de la filosofia de la conciencia kantiana. Si se aceptan la crítica lingüistica dirigida a ella y el carácter constitutivamentc lingüístico de la conciencia y la razón, sólo cabe dar cuenta de las cuestiones de validez y fundamentar la legitimidad de las elaboraciones epistémicas fácticas identificando los elementos, inevitables y máximamentc 
generales, que estăn constitutivamente presentes tanto en su formulación (enunciación) como en los procesos de aprendizaje y de revisión que llevan a corregirlas. Ahora bien, nuestras prácticas epistémicas y procesos de aprendizaje están mediados por interprestaciones lingüisticas. La investigación de sus condiciones de posibilidad tiene que scrlo, por tanto, de los presupuestos constitutivos del uso epistémico del lenguaje, uso en que se objetivan y hacen públicamente accesibles. Pero el uso del lenguaje no es el lenguaje en abstracto, como sistema que cupiera poner en correlación con una noción de pensamiento o de mente igualmente abstractas - en el sentido de la afirmación kel lenguaje... es... también un medio de constitución del pensamiento». Remite irrenunciablemente al ámbito pragmático-comunicativo de la argumentación.

En su discusión de la premisa $\left[\mathbf{P}_{3}\right]$, Acero considera que «privado» - en el sentido de la afirmación de Wittgenstein: no se puede seguir privadamente una regla- se opone a «público» («abierto», «manifiestos); considera asimismo que Apel lo interpretaría como «individual», oponiêndolo a ucomunitario". Creo, sin embargo, que lo más correcto es decir que Apel opone "privado» a intersubjetivo. $Y$, a su vez, la noción de intersubjetividad está internamente vinculada con la de validez (o de justificación racional). «Privadamente» se opone a kcon validez intersubjetiva»: no es algo sólo fácticamente público, sino susceptible de reelaboración y tevisión crítica en el habla argumentativa (discurso). Esto es mucho más que una mera precisión terminológica. Porque si se acepta, como Acero defiende, que en su lectura de Wittgenstein Apel está considerando la oposición conceptual «privado»/«público», y "público» se explica como "comunitario", entonces no se ha dado un solo paso para salvar el universalísmo que es esencial en su teoría pragmática del significado. Intersubjetividad remite a lingüisticidad; pero a una lingüisticidad no sólo de hccho compartida, sino que puede revisarse y justificar su validez en el contexto de un uso muy específico del lenguaje, el discurso; éste tiene lugar sobre la base de un conjunto de presupuestos normativos que los participantes presuponen y aceptan cada vez que argumentan, y de los que es posible mostrar su carácter universal y necesario -pues no pueden negarse explícitamente sin caer en contradicción realizativa.

La concepción intersubjetivista del lenguaje no entiende éste como un instrumento para la transmisión de rendimientos de la subjetividad, sino como el medio en que los hablantes pueden compartir intersubjetivamente $-\mathrm{y}$, en caso necesario, justificar racionalmente- la comprensión de una cosa. La teoría semiótica de Peirce permite mostrar de qué modo las elaboraciones lingüísticas están ancladas en una referencia directa a la realidad objetiva (funciones no simbólicas del lenguaje): pero objetividad no es lo mismo que verdad (o validez epistémica). Lo segundo, como categoría normativa que aplicamos a juicios cognoscitivos necesariamente linguissticos, sólo se establece discursivamente; sólo puede afirmarse que trascienda la dependencia contextual (cultural e histórica) inherente a la propia noción a partir de una reconstrucción de las condiciones que hacen posible esa legitimidad, en el seno de actividades y prácticas humanas que inevitablemente se desarrollan en la mediación de los signos lingüísticos. La universalidad que la teoría pretende ha de entenderse como una anticipación contrafáctica de lo que implícitamente se presupone en la praxis de la argumentación reflexiva en la que se revisan las preten-siones de validez problematizadas.

\section{III}

Dos son las premisas centrales en la posición kantiana de Apel que han entrado en juego en la discusion: en primer lugar, 
la contraposición entre lo fáctico y lo normativo, y la atribución de un carácter $a$ priori y constitutivo a lo segundo respecto a lo primero, en tanto los presupuestos normativos (contrafácticos) de la comunicación lingüistica son condiciones de posibilidad para ésta; en segundo lugar, el desplazamiento de esos elementos normativos desde su localización en una conciencia trascendental a su actualización en una comunidad ideal de comunicación - lo que equivale a afirmar su anticipación contrafáctica en los diálogos argumentativos reales. Pero si la comunicación linguística ha de sustituir al sujeto trascendental kantiano, parece claro que se hace imposible mantener la distinción entre lo a prioni y lo a posteriori. La insistencia de Apel en seguir manteniendo el carácter apriónico del lenguaje -como nueva instancia trascendental kantiana - se pone de manifiesto en su idea de que los significados fácticos de términos individuales - como simultaneidad, justicia, etc- - basan su validez en el presupuesto de ser una anticipación de lo que in the long run puede llegar a consensuar la comunidad ideal de intérpretes. En su lectura de Wittgenstein Apel considera que éste, al negar que pueda haber un juego de lenguaje «privilegiados: el del uso reflexivo del lenguaje que revisa críticamente su propia validez, no puede sino remitir todo sentido y todo criterio posible al conjunto de prâcticas previas; ello llevaría a Wittgenstein a una forma de holismo del significado de consecuencias realitivistas y haría inviable la defensa de una teoría universalista. $\mathrm{El}$ planteamiento de Acero no llega a poder discutir esto.

La crítica de Acero es legitima y honesta desde el punto de vista de su desarrollo argumentativo. Pero la posición intencionalista que parece defender no puede sustraerse a dificultades propias cuando rechaza el planteamiento kantiano de Apel. Pues se mueve en un trilema de difícil respuesta. $O$ bien le subyace alguna forma de naturalismo o realismo epistemológico que, salvo que encuentre el respaldo de las ciencias empíricas $-\mathrm{y}$, si se confía en ello, se está apelando a una anticipación contrafáctica para respaldar su validez-, habría que tachar de «metafísico". $O$ se ye abocado a alguna forma de relativismo o convencionalismo. $O$, finalmente, está asumiendo también una posición kantiana, si bien sustituyendo la transformación semiótica de esa filosofía trascendental por un giro intencionalista: el sujeto trascendental kantiano se convierte en un sujeto intencional, y la intencionalidad en la conciencia del sujeto pensante en el límite trascendental del sentido. 